\section{Failed discharges from the psychogeriatric ward}

Sir: We read Too's paper (Psychiatric Bulletin, August 1995, 19, 478-479) with considerable interest. We are not surprised that failed discharges come from the ranks of elderly patients with functional disorders, particularly depression. This reflects our own experience in Liverpool. Now that our dementia services for the elderly are 'mature', community care for demented patients is planned and organised with only occasional crisis readmissions due to unforeseen problems, such as acute confusional states or illhealth of caring relatives.

This is certainly not the case with services for elderly patients with functional disorders. This has become particularly apparent since it has become the policy of this department to accept all patients over the age of 65 with functional disorders. We have inherited from general psychiatric services a group of patients with very longstanding histories of depression which have become chronic, or rapidly recurrent. The finding of Jones (1991) that "The best predictor of failed discharge is the number of previous admissions" underlines the anticipated problems of transferring this group of ageing depressed patients to old age psychiatry.

Nevertheless, we would wish to make some comment on the findings of Too and her colleagues, as follows:

(1) The paper does not comment on drug regimes received by patients on discharge from hospital. The value of maintenance medication with tricyclic antidepressants and lithium in patients with recurrent depression in old age has been adequately demonstrated (Abou Saleh \& Coppen, 1983: Old Age Depression Interest Group, 1993). Were patients receiving maintenance antidepressants or lithium therapy?

(2) The authors do not mention the admission rate of patients with dementia to residential or nursing home care, which would reduce the readmission rates in the control group.

(3) Too should be encouraged to revisit this database and perhaps compare a group of elderly depressed patients with failed discharge with a group of depressed patients who have survived in the community.

Abou-SAleh, M. \& Coppen, A. (1983) The prognosis of depression in old age: the case for lithlum therapy. British Joumal of Psychiatry, 143. 527.

JONES, K. (1991) Audit in psychiatry: "falled discharges". Psychiatric Bulletin, 18, 26-27.

OLD AGE DEPRESSION INTEREST Group (1993) How long should the elderly take antidepressants? A doubleblind placebo-controlled study of continuation prophylaxds therapy with dothiepin. British Journal of Psychiatry, 162, 175-182.
R. M. PHILPOTT and D. N. ANDERSON

EMI Directorate, Sir Douglas Crawford Unit, Mossley Hill Hospital, Park Avenue. Liverpool L18 8BU

\section{Neuroleptic prescribing practice}

Sir: Milton et al (Psychiatric Bulletin. September $1995,19,575-576)$ question the value of chlorpromazine equivalents (CPZEs) but we have found them clinically useful. CPZEs, although imprecise, enable comparisons to be made between the antipsychotic activity of different neuroleptics. Where a patient is receiving more than one neuroleptic, CPZEs provide a measure of total antipsychotic activity. They are largely based on the relattve antipsychotic potencies of drugs, as determined by clinical trials, and are independent of sedattve effect. It would be helpful if a standardised table of CPZE values could be agreed. perhaps based on a meta-analysis of available reputable clinical trials and produced by the College.

By contrast, British National Formulary (BNF British Medical Association \& The Pharmaceutical Society, 1993) maximum dosages are laid down by the BNF's medical advisors and usually correspond to the dosage in the drug's product licence. They reflect safety and tolerability rather than clinically useful maximum dosage. BNF maximums may change with time, e.g. pimozide and trifluoperazine do not have one. They do not reflect antipsychotic potency, which varies approximately 20-fold between different neuroleptics. We doubt the value of Milton et al's 'ratio of maximum equivalent' (ratio of prescribed dose to that drug's BNF maximum) as a means of comparing and quantifying multiple neuroleptic drug dosages. BNF maximum dosages cannot be meaningfully compared.

Our audit of all 225 in-patients at Fair Mile (1995) found 11 patients $(5 \%)$ on neuroleptic dosages exceeding BNF maximums, in 10 cases a depot. Only one of $88(1 \%)$ acute adult in-patients exceeded a BNF maximum, but 9 of the $58(6 \%)$ rehabilitation patients did, findings similar to Torkington et al (1994) but at variance with Milton et al. Sixteen patients, all with chronic schizophrenia, received $>2000$ CPZEs a day, mostly derived from depots. High doses seemed to have been employed where conventional ones had failed to control positive psychotic symptoms and long-standing behavioural disturbance.

BRtnSH MEdical ASSOCIATION AND THE PHARMaceutical SOCIETY (1993) British National Formulary. No. 26. London: BMA \& Pharmaceutical Society.

TORKINGTON, B., HoGg, S., POWEu, G., et al (1994) Antipsychotic medication use in relation to BNF guidelines. Psychiatric Bulletin, 18, 375-376.

CAMILLA HaW and JENNY MORGaN

Fair Mile Hospital, Cholsey, Oxon OX10 9HH 